\title{
Large-scale distributions of ionospheric horizontal and field-aligned currents inferred from EISCAT
}

\author{
D. Fontaine, C. Peymirat \\ CETP-CNRS, Centre Universitaire, 10-12 Avenue de l'Europe, 78140 Vélizy, France
}

Received: 13 May 1996/Revised: 24 July 1996/Accepted: 9 August 1996

\begin{abstract}
Statistical models for large-scale convection and for ionospheric conductances were previously derived from observations of the incoherent-scatter radar EISCAT. We complete this large-scale description with statistical models of the horizontal and field-aligned currents achieved from the same data base and for the same ranges of the magnetic activity index $K p$. Except for the highlatitude dayside currents generally located poleward of the radar field of view, a large part of the whole current system can be probed with EISCAT. Globally consistent with previously published models, our results also exhibit some differences, such as the asymmetry in the local-time extension of the current sheets, concentrated to a few hours around 18 MLT in the evening sector, while widely spread from premidnight to prenoon magnetic local times on the morningside. This statistical description of the current system above EISCAT allowed us to examine several aspects of the large-scale auroral electrodynamics, namely the relationships between convection, conductances, and currents, in particular in the vicinity of the Harang discontinuity, and the features of the global current circuit.
\end{abstract}

\section{Introduction}

It is widely recognized that the current circuit coupling the ionosphere and the magnetosphere plays a dominant role in the large-scale dynamics of both regions, as well as during localized active events such as substorms. The identification of the actual signature due to disturbances requires the preliminary knowledge and a quantitative evaluation of the current circuit at the steady state from which active events can develop. This objective has first been investigated by ground-based magnetometers which

Correspondence to: D. Fontaine provide large-scale distributions of equivalent ionospheric currents and estimates of field-aligned currents (Kamide et al., 1981; Friis-Christensen et al., 1985; and references therein). Then, various instruments have been operated. From in situ measurements of the magnetic perturbations by spaceborne magnetometers, Iijima and Potemra (1976, 1978) built empirical models of field-aligned currents. Ground-based radars, which give access to the electrodynamic parameters of the ionosphere, have also contributed to this quantitative effort (see Foster et al., 1989). The AMIE technique, developed by Richmond and Kamide (1988) and applied in subsequent papers, combines simultaneous observations from different instruments to infer instantaneous maps of large-scale electric fields and currents. All these various observations contributed to major improvements in our understanding of the current system: the identification of the westward and eastward electrojets, of the poleward region 1 and the equatorward region 2 of field-aligned currents, the role of the interplanetary magnetic field (IMF) on the high-latitude current distribution, and the estimation of the current intensities for different magnetic activity conditions.

The European incoherent-scatter radar facilities (EISCAT) may expand this already-rich context, at first for instrumental reasons. The unique tristatic capabilities of the UHF radar give access to accurate and direct measurements of the plasma-velocity vectors and thus to reliable distributions of convection electric fields. Then, the electric field combines with the height-integrated conductances, derived from the electron density profiles simultaneously measured, to infer the horizontal and field-aligned currents. Finally, a single instrument, EISCAT, can achieve observations of a full electrodynamic state of the local ionospheric plasma. This advantage opens the field to more detailed investigations on fundamental and still controversial questions, addressing the relationships between convection, conductances, and currents, their individual role in the ionospheric electrodynamics, and the features of the current circuit in high-latitude regions. 
Prior to estimating in the future the proper signature of active and localized events, and to avoid mixing them with previously existing features, we concentrate here on largescale time-averaged patterns. Senior et al. (1990) and Senior (1991) made use of the EISCAT data base to derive, respectively, statistical models of the large-scale convection and of the height-integrated conductances for ranges of magnetic activity keyed to the index $K p$. This set of empirical models is completed here by the derivation of the statistical ionospheric and field-aligned currents from the same data base and in the same magnetic conditions. We also discuss their contribution to the auroral electrodynamics.

\section{Data analysis}

\subsection{Operating modes and data base}

The UHF system of EISCAT operates at $935 \mathrm{MHz}$ with three sites in North Scandinavia: one transmitting-receiving system at Tromsö (Norway), and two receiving antennas at Kiruna (Sweden) and Sodankylä (Finland). We took advantage of the tristatic capabilities of EISCAT to infer horizontal and field-aligned currents at auroral latitudes. Their large-scale distribution is best probed by the operating modes of elevation scans in the magnetic meridian plane of Tromsö. Like Senior et al. (1990), we make use of the EISCAT data base for the scanning experiments, Common Programs CP-3C and CP-3E, covering the invariant latitudinal range $61.5^{\circ}-71.5^{\circ}$ and $61^{\circ}-72.5^{\circ}$, respectively, with a cycle time of $30 \mathrm{~min}$. The data are post-integrated over the dwell time at each position. The data set, described by Senior et al. (1990), involves about $900 \mathrm{~h}$ (more than 25000 data points) of CP-3 analyzed data between June 1984 and November 1987. From the power and frequency spectrum measurements of the backscattered signal along the line of sight of the transmittingreceiving site at Tromsö, we infer the field-aligned profiles of the electron density in the $\mathrm{E}$ and $\mathrm{F}$ regions, and of electron and ion temperatures in the $\mathrm{F}$ region. In addition, the three-dimensional ion drifts are measured in the $\mathrm{F}$ region at the intersection point of the three beams, at the constant altitude of 325 and $275 \mathrm{~km}$ for CP-3C and CP$3 \mathrm{E}$, respectively. Further technical details are described by Folkestadt et al. (1983). Following Caudal and Blanc (1988), the determination of the three components of the ion drift can be improved by the addition of an extra constraint, applied at every measurement point, and particularly useful in the less favorable conditions of the beam geometry. It consists in describing the field-aligned velocity, known to be small, by a Gaussian probability distribution centered around $0 \mathrm{~m} / \mathrm{s}$ with a standard error of $60 \mathrm{~m} / \mathrm{s}$. The most probable vector is then evaluated from this information in addition to the tristatic measurements.

\subsection{Derivation of currents}

The electric-current density $\boldsymbol{j}$ at the ionospheric level obeys Ohm's law and the current continuity equation, given by:

$\boldsymbol{j}=\sigma \cdot\left(\boldsymbol{E}+\boldsymbol{V}_{\mathrm{n}} \times \boldsymbol{B}\right)$,

$\operatorname{div} \boldsymbol{j}=0$,

respectively, where $\sigma$ is the conductivity tensor, $\boldsymbol{E}$, the electric field, $\boldsymbol{V}_{n}$, the neutral wind, and $\boldsymbol{B}$ the magnetic field. The electric field $\boldsymbol{E}$ is derived from measurements of F-region ion drift $\boldsymbol{V}_{i}$ :

$\boldsymbol{E}=-\left(\boldsymbol{V}_{i} \times \boldsymbol{B}\right)$.

We proceed similarly to Yashura et al. (1982) for Millstone Hill data and Caudal (1987) for EISCAT data. Neglecting neutral winds, the height integration of Eqs. 1 and 2 yields the expression of the northern $(\mathrm{N})$ and eastern (E) components of the height-integrated horizontal currents $\boldsymbol{J}$ :

$\left(\begin{array}{l}J_{\mathrm{N}} \\ J_{\mathrm{E}}\end{array}\right)=\left(\begin{array}{ll}\Sigma_{\mathrm{P}} / \sin ^{2} I & -\Sigma_{\mathrm{H}} / \sin \mathrm{I} \\ \Sigma_{\mathrm{H}} / \sin I & \Sigma_{\mathrm{P}}\end{array}\right) \cdot\left(\begin{array}{l}E_{\mathrm{N}} \\ E_{\mathrm{E}}\end{array}\right)$,

and of the field-aligned current density $j_{\|}$(positive into the ionosphere):

$j_{\|} \sin I=\operatorname{div} \boldsymbol{J}$

where $I$ is the magnetic-field inclination and $\Sigma_{\mathrm{p}}$ and $\Sigma_{\mathrm{H}}$ the Pedersen and Hall height-integrated conductivities, respectively. Finally, the electric-current system can be fully determined from EISCAT data, with the tristatic measurements of electrostatic electric fields in the $\mathrm{F}$ region, and with the height-integrated conductivities derived from electron density profiles in the $\mathrm{E}$ region. However, due to the fan-shaped geometry of the scans, the latitudinal coverage of the observations depends on the altitude. Extended to some $10^{\circ}$ in the $\mathrm{F}$ region, it reduces to typically $3^{\circ}-4^{\circ}$ at the lower altitudes of the conductive $\mathrm{E}$ region, thus limiting the experimental determination of the ionospheric conductivities, and of the currents, to this narrow range. To take advantage of the full set of the electric-field measurements in the F region by EISCAT, models or extrapolations are required to extend the conductivity distribution apart from the central zone of the observations. Ahn et al. (1989) demonstrated that in spite of significant differences between statistical and instantaneous conductances, the resulting electrodynamic parameters showed remarkable similarities as far as global features were concerned. A similar procedure was already applied by Caudal (1987), who made use of the model of conductivity developed by Wallis and Budzinski (1981) for $24 \mathrm{~h}$ of EISCAT observations during a quiet summer day.

\subsection{Model of ionospheric conductances}

The ionospheric conductances result from the contribution of two main ionization sources, usually approximated by a quadratic sum:

$$
\Sigma_{\mathrm{P}, \mathrm{H}}=\sqrt{\left(\left(\sum_{\mathrm{P}, \mathrm{H}}^{\mathrm{S}}\right)^{2}+\left(\sum_{\mathrm{P}, \mathrm{H}}^{\mathrm{P}}\right)^{2}\right.} \text {. }
$$


The effect of the UV and EUV solar illumination mainly depends on the solar zenith angle $\chi$, and several empirical models of solar-induced conductances $\Sigma_{\mathrm{P}, \mathrm{H}}^{\mathrm{S}}$ were built from data of incoherent-scatter radars, including EISCAT (Vickrey et al., 1981; Robinson and Vondrak, 1984; Schlegel, 1988; Brekke and Hall, 1988). The contribution of magnetospheric particle precipitations $\Sigma_{\mathrm{P}, \mathrm{H}}^{\mathrm{P}}$, which exhibits stronger spatial and temporal variations mainly related to the magnetic activity, is more difficult to derive from incoherent-scatter data, due to the limited coverage in the $\mathrm{E}$ region. Global patterns of average characteristics of electron precipitation inferred from satellite data were combined with mathematical techniques to estimate the ionospheric electron profiles and the resulting conductance enhancements, according to indices of geomagnetic activity such as $A E, K p$, or a precipitation index (Reiff, 1984; Hardy et al., 1987; FullerRowell and Evans, 1987).

Recently, from the EISCAT data base of CP-3 experiments used in this study, Senior (1991) could separate and model the respective contributions of both sources to conductances. The empirical dependence on the solar zenith angle $\chi$ of solar-induced conductances was best fitted by:

$\Sigma_{\mathrm{P}}^{\mathrm{S}}=1.81+\cos \chi$,

$\Sigma_{\mathrm{H}}^{\mathrm{S}}=21.58-0.21 \chi$.

The $K p$ dependence of the precipitation-induced conductances was then estimated from the difference between observations and this model of the sun-induced contribution. It globally agrees with the results at EISCAT latitude of the global statistical model developed by Hardy et al. (1987) from electron precipitation fluxes detected on board the satellites DMSP. A systematic underestimation of DMSP predictions in the evening sector was suggested to result from the absence of ion-precipitation effects, probably contributing to ionospheric conductances in this local time sector.

For the present study, we select the model of ionospheric conductances able to suit at best the conditions of each measurement included in our data base, and to provide predictions over the extended latitudinal coverage of EISCAT scans. Following the preceding study by Senior (1991) for the same data base, we adopt:

1) For the solar-induced conductances $\Sigma_{\mathrm{P}, \mathrm{H}}^{\mathrm{S}}$ : the empirical model proposed by Senior (1991), depending on the solar zenith angle as given by Eq. 7, and especially built for the data base that we use.

2) For the precipitation-induced conductances $\Sigma_{\mathrm{P}, \mathrm{H}}^{\mathrm{S}}$ : the global statistical model developed by Hardy et al. (1987) as a function of the geomagnetic index $K p$, and available at all local times and over a wide range of latitudes including the EISCAT field of view. Senior (1991) demonstrated that it agreed reasonably well with our data set, both in amplitude and in phase. The discrepancy the evening sector already mentioned, expected to have only a minor effect for large-scale statistics on ionospheric currents, will be discussed.

\section{Ionospheric currents}

\subsection{Statistical methods}

For each measurement point included in the data base, the northward and eastward components of the heightintegrated horizontal current are derived from Eq. 4, with the electric field deduced by Eq. 3 from the ion-drift measurement in the $\mathrm{F}$ region, and with the conductance model described above. We exploit the same EISCAT data base and follow the same statistical procedure for horizontal currents as Senior et al. (1990) for the electric fields. The 25000 observations of horizontal currents are similarly classified according to the three ranges of the magnetic-activity index $K p: 0<K p<2-, \quad 2<K p$ $<4-, 4<K p<6-$. Then, for each $K p$ range, the current components are averaged over bins of $1^{\circ}$ latitude and $1 \mathrm{~h}$ magnetic local time (MLT). The averaging procedure includes a weight factor inversely proportional to the square of the error.

The relevance of the conductance model is tested by substituting to the value, predicted for each measurement, the conductance actually observed by EISCAT in the $\mathrm{E}$ region along the magnetic field lines connected to the measurement points of electric fields in the $\mathrm{F}$ region. As already indicated, the use of observed conductances limits the derivation of the horizontal currents to the central latitudinal range of the scans, where they are available. Then, we apply the same averaging procedure as above, resulting in a new set of statistical current distributions for each of the three $K p$ classes. Figure 1 displays the MLT variations of the statistical northward (full line) and eastward (dashed line) components of the horizontal currents, derived (a) with observed conductances, and (b) with the conductance model described, at the central invariant latitude $\left(67^{\circ}\right)$. The amplitude of both components increases substantially with the magnetic activity, with a maximum around $0.05 \mathrm{~A} / \mathrm{m}$ for quiet situations (top panel), $0.2 \mathrm{~A} / \mathrm{m}$ for moderate activity (middle panel), and $0.5 \mathrm{~A} / \mathrm{m}$ for disturbed situations (bottom panel). In all cases, the agreement in phase and amplitude of both components between the two statistical sets shows that the current distribution derived with the conductance model reproduces reasonably well the general slopes and main trends of the observations. A more detailed comparison reveals identical behaviors on the dayside. For the higher $K p$ and on the nightside of the auroral oval, the observed currents exhibit slightly stronger intensities with larger fluctuations than with the model, expected somewhat to smooth out the amplitude of the variations. Indeed, as demonstrated by Hardy et al. (1985) and Foster et al. (1986), the contribution of precipitations in this sector is expected to be both dominant and highly variable. This is also confirmed by the statistical studies of precipitation-induced conductances (Fuller-Rowell and Evans, 1987; Senior, 1991): the noisy behavior and the large scatter around the mean value of the auroral conductances on the nightside, both increasing with magnetic activity, are explained by the frequent occurrence and the dynamics of small-scale precipitation structures. Apart from this expected discrepancy, relatively minor for 

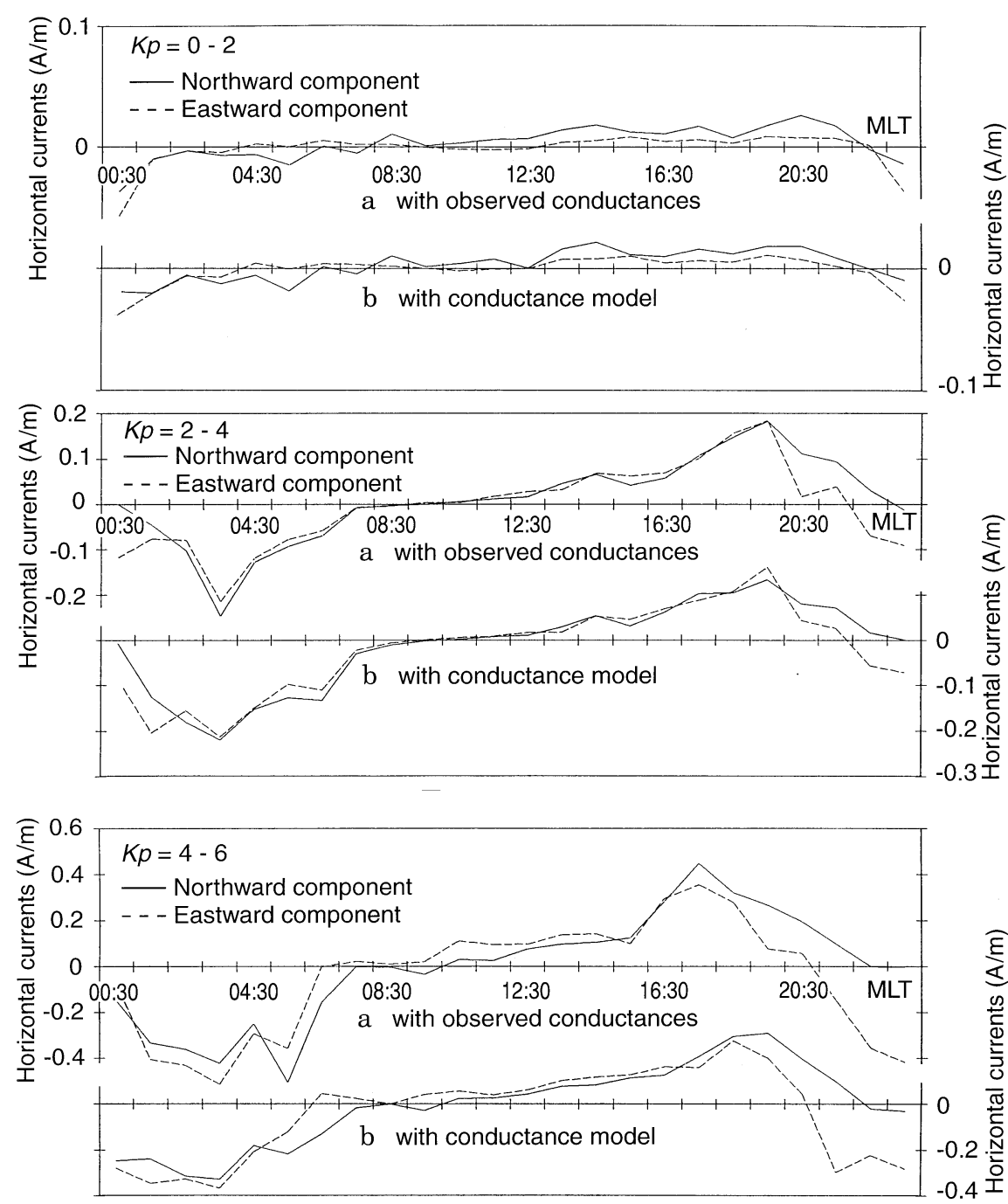

\section{包}

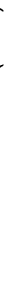

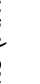
政 
$0<K p<2$

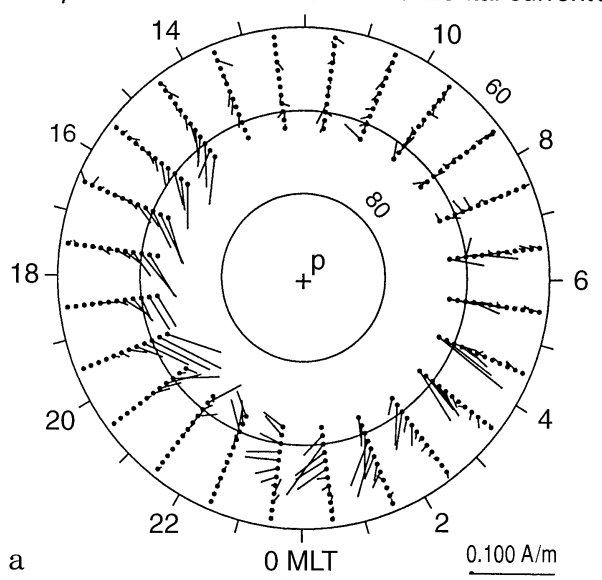

$2<K p<4 \quad 12$ Horizontal currents

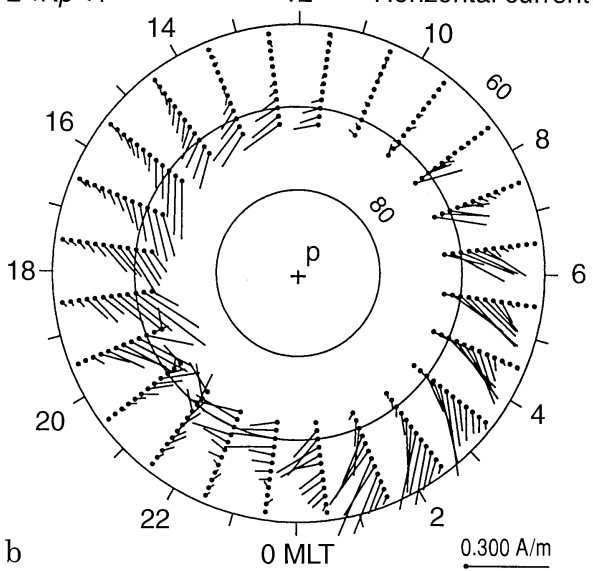

$4<K p<6 \quad 12$ Horizontal currents

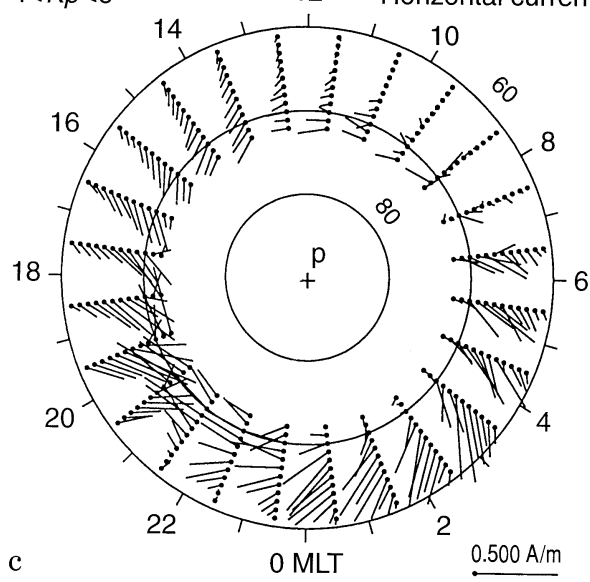

Fig. 2. Polar distributions of the statistical height-integrated horizontal currents for the three magnetic-activity ranges (note that the vector scale, indicated at the bottom of each part, increases with magnetic activity)

(dashed line) current components, and for the three $K p$ ranges. With the use of a conductance model, the only source of error is the measured electric field, and, not surprisingly, the global trends meet the conclusions of Senior et al. (1990) in the companion statistics on electric fields. The general level increases with magnetic activity,

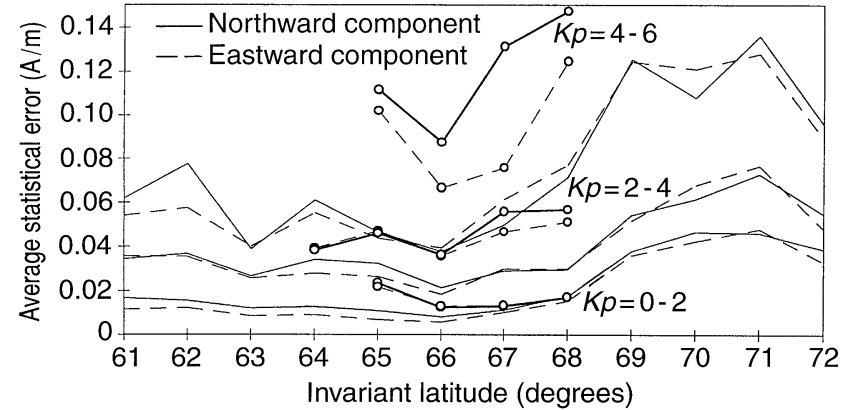

Fig. 3. Latitudinal variation of the 24 -h-averaged statistical errors on the northward (full lines) and eastward (dashed lines) current components for the three magnetic-activity ranges. Continuous lines refer to currents derived with conductance models and lines with open circles with observed conductances

with weakest errors at central latitudes of the field of view. The errors over the poleward part exceed the equatorward values: this characteristic feature was already interpreted by Senior et al. (1990) as the effects at poleward latitudes, partly of a less favorable tristatic configuration, and mainly of the extreme variability of the plasma flow in presence of frequent localized or short-lived events. The influence of the second source of error (i.e., on the conductances) would obviously increase the general error level. It can be estimated over the limited range of central latitudes from statistics involving both conductance and velocity measurements (previous case a). The resulting statistical errors on both current components, similarly averaged over $24 \mathrm{~h}$ at each latitude, are plotted in Fig. 3 by curves with open circles. Despite the limited number of points, the errors exhibit similar trends with expected larger amplitudes, reaching at places up to twice the value in the previous case with the conductance model (case b). Finally, the error amplitudes vary, respectively, between $0.01-0.04,0.02-0.07$, and $0.04-0.12 \mathrm{~A} / \mathrm{m}$ as the magnetic activity increases. The comparison to statistical current intensities, typically scaling as $0.1,0.3$, and 0.5 , respective$1 y$, tends to conclude that the current statistics reproduce reasonably well the main features of the horizontal current circulation.

\section{Field-aligned currents}

\subsection{Computation and model}

The computation of field-aligned currents, as the divergence of height-integrated horizontal currents by Eq. 5, assumes the time stationarity during successive scans. This condition is better met by a statistical distribution of horizontal currents than by the current pattern inferred from any individual experiment included in the data base, since the averaging procedure tends to cancel out space and time small-scale variations. In consequence, we compute statistical distributions of field-aligned currents by taking directly the divergence of the statistical ionospheric currents derived in the preceding section for the three magnetic-activity classes. At each point, the divergence is 
Table 1. Coefficients of the polynomial expansion for the model of the field-aligned currents

\begin{tabular}{|c|c|c|c|c|c|c|c|c|c|c|c|}
\hline & \multirow{2}{*}{$\begin{array}{l}m=0 \\
\text { An0 }\end{array}$} & \multicolumn{2}{|c|}{$m=1$} & \multicolumn{2}{|c|}{$m=2$} & \multicolumn{2}{|c|}{$m=3$} & \multicolumn{2}{|c|}{$m=4$} & \multicolumn{2}{|c|}{$m=5$} \\
\hline & & An1 & Bn1 & An2 & $\mathrm{Bn} 2$ & An3 & $\mathrm{Bn} 3$ & An4 & $\mathrm{Bn} 4$ & An5 & Bn5 \\
\hline \multicolumn{12}{|c|}{$K p=0-2$} \\
\hline $\begin{array}{l}n=0 \\
n=1 \\
n=2 \\
n=3 \\
n=4 \\
n=5\end{array}$ & $\begin{array}{r}-0.006 \\
0.012 \\
-0.026 \\
-0.000 \\
-0.043 \\
0.019\end{array}$ & $\begin{array}{r}-0.014 \\
0.013 \\
-0.031 \\
0.013 \\
-0.044 \\
0.012\end{array}$ & $\begin{array}{r}-0.023 \\
-0.018 \\
0.036 \\
-0.067 \\
-0.019 \\
-0.000\end{array}$ & $\begin{array}{r}0.010 \\
-0.004 \\
0.045 \\
-0.012 \\
-0.024 \\
-0.010\end{array}$ & $\begin{array}{r}0.001 \\
-0.025 \\
0.015 \\
0.005 \\
-0.080 \\
0.074\end{array}$ & $\begin{array}{r}0.016 \\
0.005 \\
0.045 \\
-0.008 \\
0.023 \\
-0.017\end{array}$ & $\begin{array}{r}0.006 \\
-0.018 \\
0.001 \\
-0.035 \\
-0.000 \\
-0.056\end{array}$ & $\begin{array}{r}0.005 \\
-0.008 \\
-0.019 \\
0.052 \\
-0.031 \\
0.008\end{array}$ & $\begin{array}{r}0.027 \\
-0.012 \\
0.037 \\
0.005 \\
-0.009 \\
-0.002\end{array}$ & $\begin{array}{r}-0.002 \\
-0.009 \\
0.002 \\
-0.013 \\
-0.036 \\
0.023\end{array}$ & $\begin{array}{r}0.012 \\
-0.004 \\
-0.003 \\
-0.005 \\
0.045 \\
-0.039\end{array}$ \\
\hline $\begin{array}{l}K p=2 \\
n=0 \\
n=1 \\
n=2 \\
n=3 \\
n=4 \\
n=5\end{array}$ & \begin{tabular}{r}
\multicolumn{1}{l}{} \\
-0.014 \\
-0.015 \\
-0.002 \\
0.031 \\
-0.016 \\
0.003
\end{tabular} & $\begin{array}{r}-0.041 \\
-0.046 \\
0.013 \\
0.001 \\
0.033 \\
-0.043\end{array}$ & $\begin{array}{r}-0.004 \\
-0.234 \\
0.299 \\
-0.067 \\
0.022 \\
-0.064\end{array}$ & $\begin{array}{r}0.016 \\
-0.062 \\
-0.010 \\
0.113 \\
0.022 \\
0.070\end{array}$ & $\begin{array}{r}0.071 \\
-0.276 \\
0.146 \\
-0.002 \\
0.008 \\
0.042\end{array}$ & $\begin{array}{r}-0.011 \\
0.009 \\
-0.015 \\
-0.020 \\
0.078 \\
0.031\end{array}$ & $\begin{array}{r}0.005 \\
-0.018 \\
-0.163 \\
0.059 \\
-0.068 \\
0.010\end{array}$ & $\begin{array}{r}0.009 \\
-0.015 \\
0.086 \\
-0.082 \\
0.095 \\
0.074\end{array}$ & $\begin{array}{r}-0.020 \\
0.055 \\
-0.115 \\
-0.030 \\
0.050 \\
0.015\end{array}$ & $\begin{array}{r}0.010 \\
0.013 \\
0.049 \\
-0.058 \\
-0.007 \\
0.004\end{array}$ & $\begin{array}{r}-0.012 \\
-0.031 \\
0.038 \\
-0.113 \\
0.053 \\
-0.045\end{array}$ \\
\hline $\begin{array}{l}K p= \\
n=0 \\
n=1 \\
n=2 \\
n=3 \\
n=4 \\
n=5\end{array}$ & $\begin{array}{l}6 \\
-0.037 \\
-0.053 \\
-0.042 \\
-0.032 \\
-0.035 \\
-0.013\end{array}$ & $\begin{array}{r}-0.053 \\
-0.167 \\
-0.021 \\
0.018 \\
0.031 \\
-0.033\end{array}$ & $\begin{array}{r}0.121 \\
-0.423 \\
0.045 \\
0.321 \\
-0.291 \\
-0.066\end{array}$ & $\begin{array}{r}0.039 \\
-0.214 \\
0.010 \\
0.056 \\
0.190 \\
-0.193\end{array}$ & $\begin{array}{r}0.078 \\
-0.138 \\
-0.162 \\
0.320 \\
-0.109 \\
-0.074\end{array}$ & $\begin{array}{r}0.055 \\
-0.009 \\
-0.172 \\
0.177 \\
-0.004 \\
-0.046\end{array}$ & $\begin{array}{r}0.018 \\
0.094 \\
-0.076 \\
-0.002 \\
0.061 \\
-0.075\end{array}$ & $\begin{array}{r}0.035 \\
0.050 \\
-0.023 \\
-0.036 \\
0.150 \\
0.104\end{array}$ & $\begin{array}{r}-0.043 \\
0.043 \\
0.118 \\
-0.105 \\
-0.145 \\
0.192\end{array}$ & $\begin{array}{r}0.002 \\
-0.047 \\
0.011 \\
-0.077 \\
0.103 \\
-0.089\end{array}$ & $\begin{array}{r}-0.023 \\
-0.044 \\
0.149 \\
-0.139 \\
-0.013 \\
0.219\end{array}$ \\
\hline
\end{tabular}

approximated by the mean value of the finite differences between the horizontal current components at this point and the corresponding components at the two closest adjacent points in each considered direction.

Finally, the last step consists in achieving $K p$-dependent statistical models of field-aligned currents by a fitting procedure, in the least-square sense, with a theoretical function involving an expansion in Legendre polynomials depending on latitude combined with a Fourier analysis in MLT. Such an expansion was originally developed by Alcaydé et al. (1986) to model the large-scale convection from EISCAT data, and then applied by Fontaine et al. (1986), Senior et al. (1990), and de la Beaujardière et al. (1991). The fit is performed up to the fifth polynomial degree and the fifth time harmonic $(n=5$ and $m=5$, in Alcaydé's notation).

$j_{\|}=\sum_{n=0}^{5} \sum_{m=0}^{5}\left(\left(A_{n m} \cos (m \varphi)+B_{n m} \sin (m \varphi)\right) P_{n}(x)\right.$,

with $\varphi$ (MLT) expressed in angular units and counted from midnight.

The Legendre Polynomials $P_{n}$ depend on the invariant latitude $\Lambda$, through the normalized parameter $x$ :

$x=\left(2 \Lambda-\Lambda_{\max }-\Lambda_{\min }\right) /\left(\Lambda_{\min }-\Lambda_{\max }\right)$,

where $\Lambda_{\max }$ and $\Lambda_{\min }$, the extremum invariant latitudes of the statistics, are equal to $72^{\circ}$ and $61^{\circ}$, respectively. The coefficients $A_{n m}$ and $B_{n m}$ are listed in Table 1 for the three considered classes of $K p$.

\subsection{Results}

The resulting fitted distributions of field-aligned currents for the three classes of magnetic activity are displayed in Fig. 4 with polar diagrams similar to Fig. 2. They represent the current densities exceeding $0.1 \mu \mathrm{A} / \mathrm{m}^{2}$ by isocontours at intervals of $0.1 \mu \mathrm{A} / \mathrm{m}^{2}$, with full lines for downward currents and dashed lines for upward currents. Both values are set to $0.075 \mu \mathrm{A} / \mathrm{m}^{2}$ in the case of the lowest magnetic activity (Fig. 4a). The expected characteristics of the field-aligned current system can be clearly identified according to the initial description of Iijima and Potemra (1976, 1978): an equatorward sheet (region 2) with currents flowing downward in the evening sector and upward in the morning sector, and a poleward sheet (region 1) with opposite polarities. Obviously, the radar field of view does not reach latitudes poleward enough to detect unambiguously the dayside current system at high latitudes. The case of the lowest magnetic activity (Fig. 4a) cannot be discussed in great detail because of the weak current densities, with maxima around $0.1-0.2 \mu \mathrm{A} / \mathrm{m}^{2}$. When the magnetic activity increases moderately (Fig. 4b), and except around noon again, part of the region-1 currents appears at the poleward latitudes of the radar field of view, with an upward flow in the evening sector and a downward flow in the morning sector, and peak intensities slightly exceeding $1 \mu \mathrm{A} / \mathrm{m}^{2}$. Equatorward of them, region-2 currents expand over a large part of the latitudinal range with densities typically of the order of $0.4 \mu \mathrm{A} / \mathrm{m}^{2}$. A strong evening-morning asymmetry can be noticed between the downward currents mainly concentrated from 16 to 21 MLT and the upward currents 

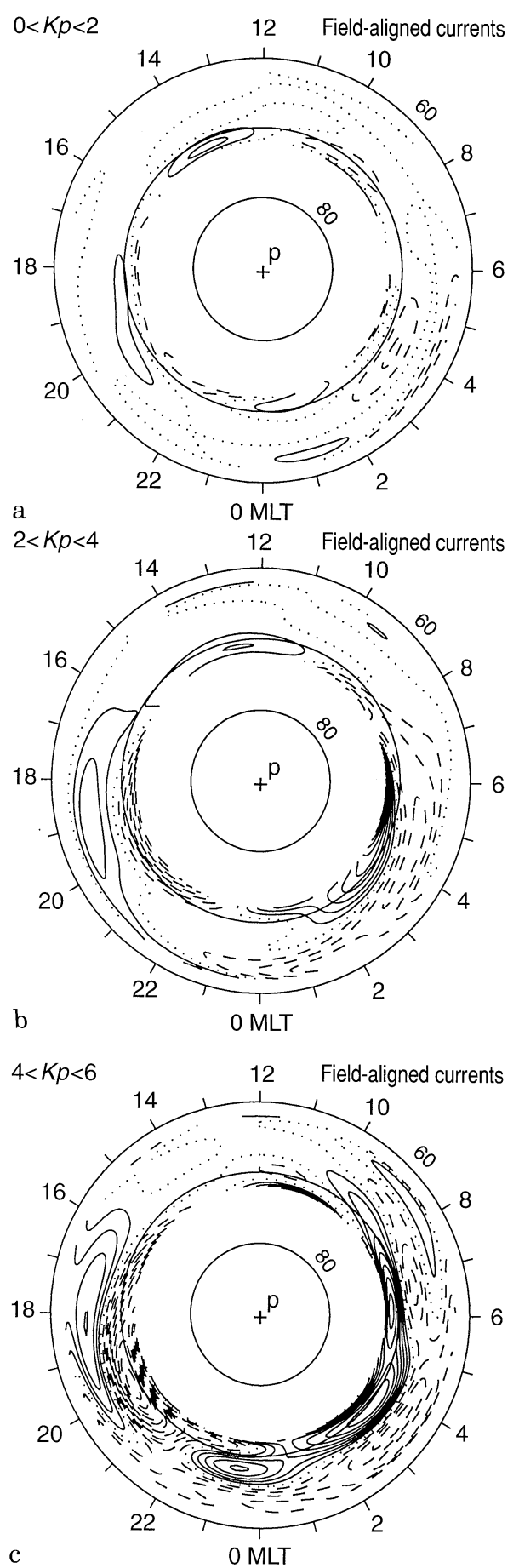

Fig. 4. Polar distribution of field-aligned currents for the three magnetic-activity ranges. Full lines represent downward currents, dashed lines upward currents. The contour threshold and intervals are set to $0.1 \mu \mathrm{A} / \mathrm{m}^{2}\left(0.075 \mu \mathrm{A} / \mathrm{m}^{2}\right.$ for $\left.K p=0-2\right)$

covering a wider MLT range from 23 to 08 MLT, with largest densities around 02-06 MLT. For disturbed situations (Fig. 4c), the whole pattern moves equatorward, except around noon where the current densities remain negligible. Region-1 currents are now evidenced over a little more than the poleward half of the radar field of

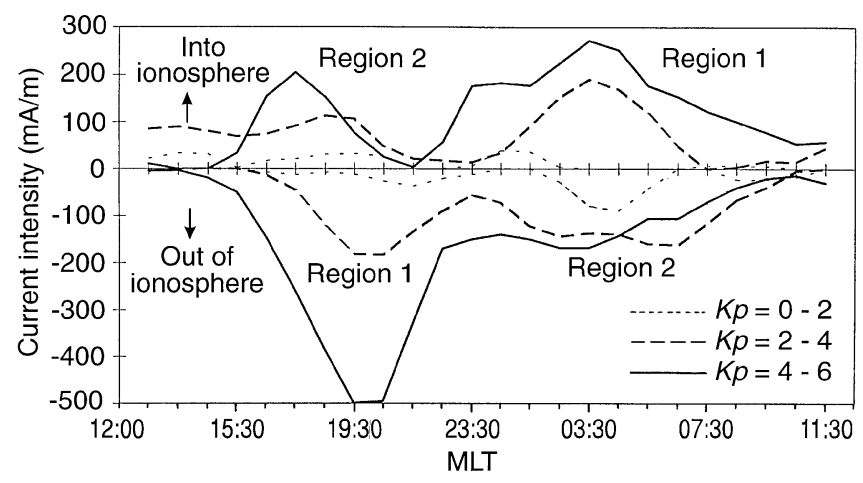

Fig. 5. Local-time variation of upward and downward current densities integrated in latitude over EISCAT field of view for $K p=0-2$ (dotted lines), 2-4 (dashed lines), and 4-6 (full lines)

view at least on the nightside, with intensities exceeding $1.5 \mu \mathrm{A} / \mathrm{m}^{2}$, while the region- 2 currents are confined to the equatorward part of the field of view, with typical intensities of $0.6 \mu \mathrm{A} / \mathrm{m}^{2}$. As previously, the global pattern exhibits again a strong asymmetry, with the evening sheets of both regions, centered around 18 MLT over a few MLT, and much less developed than the morning sheets typically spread from 22 MLT and over the whole morning sector. Indeed, these statistical distributions resemble instantaneous patterns performed by Richmond et al. (1988) from the AMIE technique. There is also an indication of an overlap of multiple sheets in the premidnight sector.

The main features of the field-aligned current system observed within the field of view of the radar, thus excluding the dayside cusp currents apparently flowing at higher latitudes, globally agree in location, density, and dynamics with previously published quantitative descriptions (Iijima and Potemra, 1976, 1978; Friis-Christensen et al., 1985; Foster et al., 1989). Both regions 1 and 2 consist of narrow current sheets, limited to a few latitudinal degrees, which expand equatorward and intensify with magnetic activity. Upward currents of regions 1 and 2 are continuous over the nightside, while downward currents of both regions form fully separated sheets. Multiple current sheets overlap in the premidnight sector. The current density is statistically larger in region 1 than in region 2, in agreement with Iijima and Potemra (1978). A more quantitative estimate can be discussed from Fig. 5, which displays the local time variation of the density integrated in latitude over the radar field of view for the three ranges of magnetic activity. The case of the lowest $K p$ is also represented, but is not of great interest, because of the weak currents and the absence of observations in region 1 . At higher $K p$, the local time variations resemble the results, keyed to a precipitation index, of Foster et al. (1989), within the restriction that the polarmost part of region 1 in the early afternoon might remain outside the radar field of view. Even so, the integrated intensity is consistent with their results. However, the current intensity statistically larger in region 1 than in region 2 meets a better agreement with Iijima and Potemra (1978). The total amount of upward current integrated over the EISCAT 
field of view approximately balances the total downward current. Their increase with magnetic activity scales, respectively, as 0.4, 1.3, 2.9 MA, and 0.3, 1.2, 2.3 MA, for the three $K p$ ranges. Because part of the current pattern, at least the high-latitude dayside system, is not probed by EISCAT, these intensities are expected to be underestimated relative to previously published statistics (Iijima and Potemra, 1978; Foster et al., 1989). However, the underestimation is slight enough to suggest that EISCAT is observing a substantial part of the whole current system. Finally, a morning-evening asymmetry can be clearly identified in the radar field of view: the evening sheets are mostly concentrated, roughly between 1600 and 2200 MLT, while the morning sheets extend widely from premidnight to prenoon local times. This asymmetry holds obviously for region-2 sheets, clearly evidenced within the field of view; although strongly suggested, it remains more uncertain for region-1 sheets which might spread at somewhat higher latitudes, in particular on the dayside.

\section{Discussion}

The achievement of this $K p$-dependent statistical model of currents completes the previously published statistics from the same EISCAT data base on the convection electric fields and the ionospheric conductances (Senior et al., 1990; Senior, 1991). This consistent set of statistics gives the opportunity to discuss different aspects of the large-scale auroral electrodynamics in steady situations. In the following, we disregard the case of the lowest $K p$ range $(K p=0-2)$, because part of the current circulation (region 1) remains poleward of the EISCAT field of view.

\subsection{Convection, conductances, and currents}

The first aspects that we consider are the relationships between the convection pattern, the auroral precipitation oval, and the current circulation. Figures 6 and 7 (for $K p=2-4$ and $K p=4-6$ respectively) display in rectangular diagrams (MLT, invariant latitude) the statistical
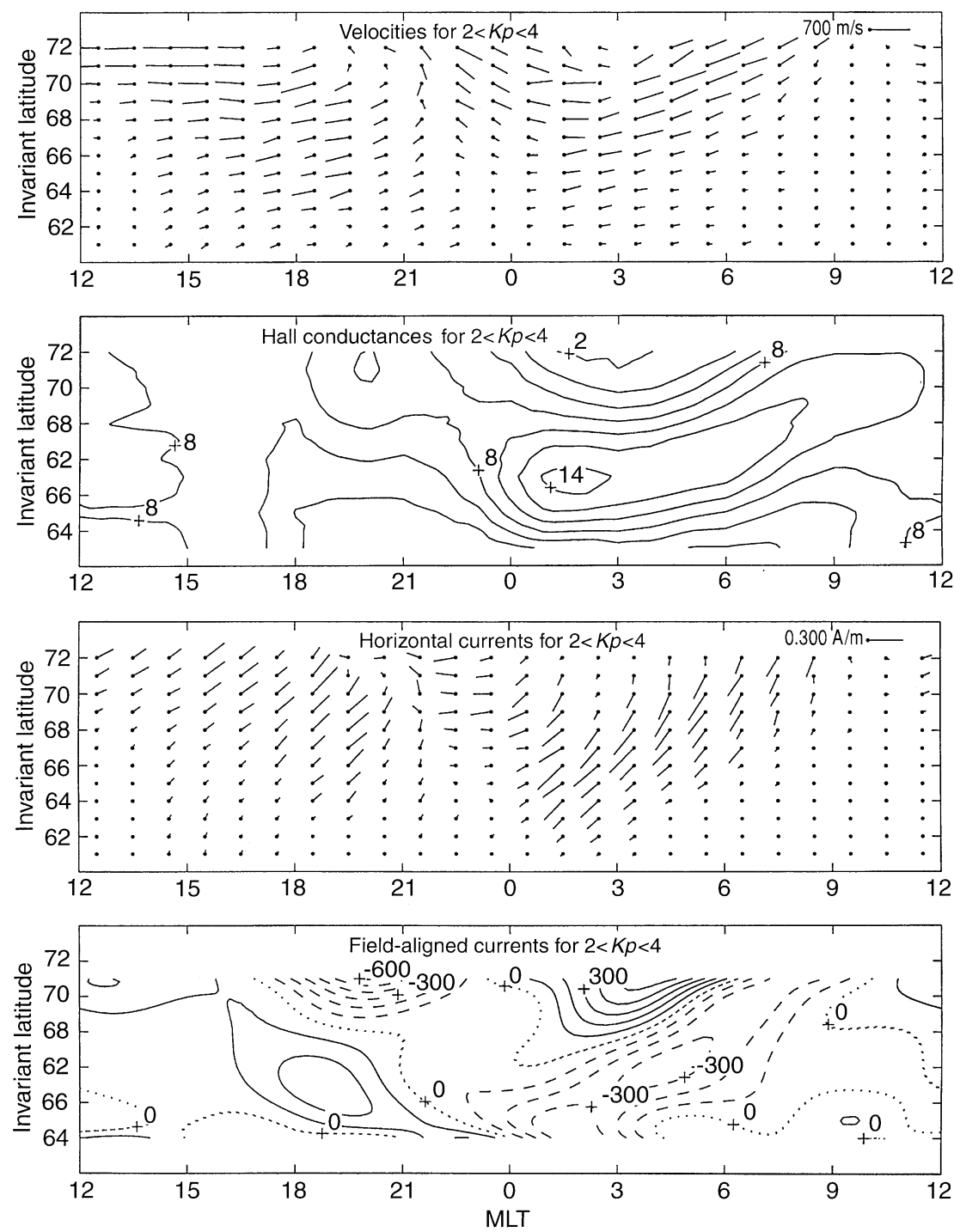

Fig. 6. Statistical distributions for $K p=2-4$ of convection velocities, Hall conductances (mhos), height-integrated horizontal currents, and fieldaligned currents (downward currents with full lines, upward currents with dashed lines); the current intensities are expressed in $\mathrm{nA} / \mathrm{m}^{2}$ 

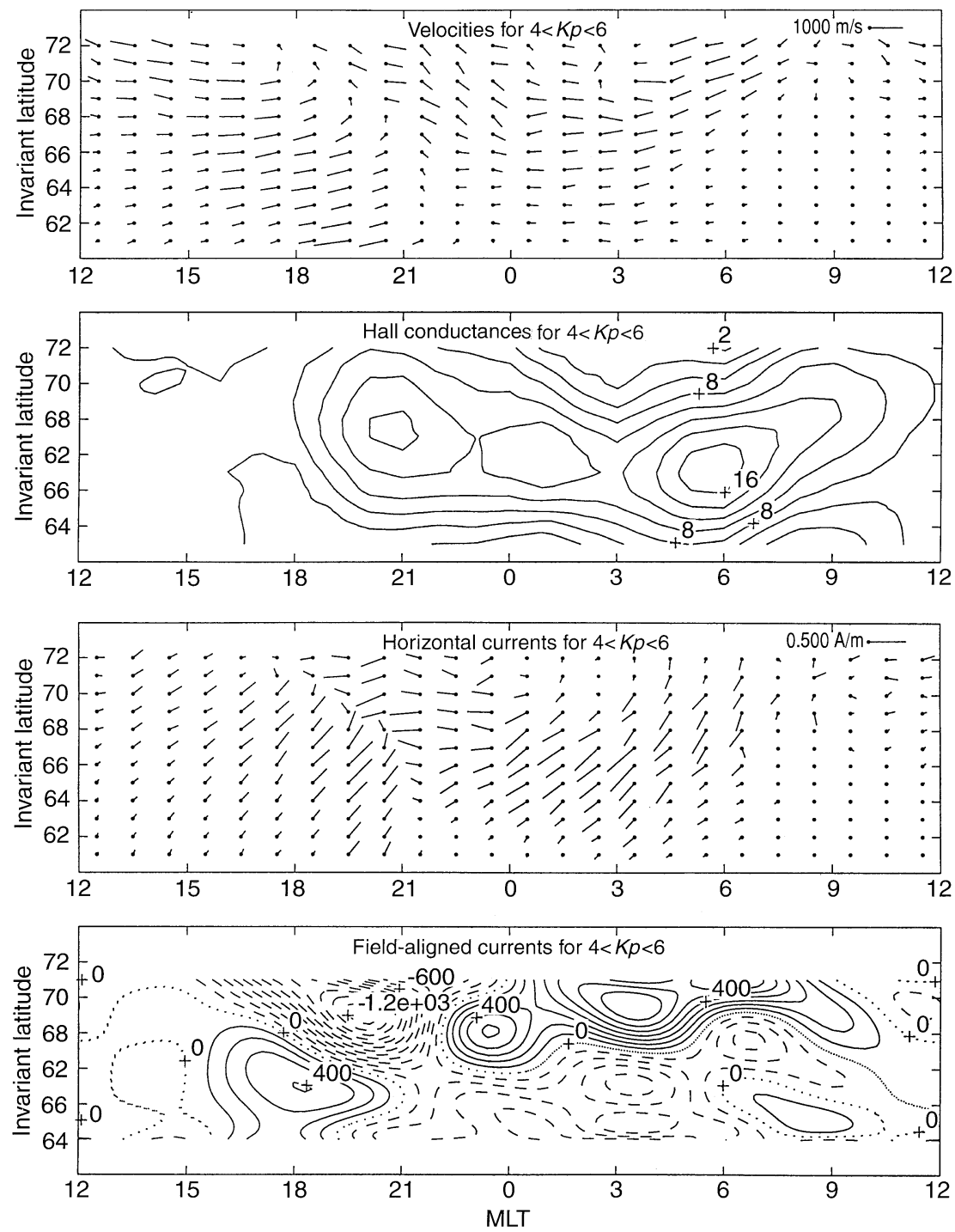

Fig. 7. Same as Fig. 6 for $K p=4-6$

distributions of plasma-drift velocities, Hall conductances, and horizontal and field-aligned currents. In this representation, the oval of enhanced conductances extends over a wide night sector, typically between 1800 and 900 MLT, with the central part displaced by 1 or $2 \mathrm{~h}$ relative to midnight. It exhibits the well-known crescent shape reaching latitudes lower in the night than at both morning and evening ends (Hardy et al., 1987).

The largest convection velocities are statistically observed over the afternoon sector, and at nighttime in regions of conductivity gradients at the poleward edge of the auroral zone. As a result, the intense antisunward convection flow from the polar cap toward lower latitudes on the nightside encounters a region of increasing (decreasing) conductances in the premidnight (evening) sector of the auroral oval, which contributes to deflect it toward the morning- (afternoon-) side. Indeed, this is another illustration of the velocity deflection effect by conductivity gradients, widely mentioned in the literature: for example, the asymmetry of the morning and evening convection cells is explained by the day/night conductivity gradient (Wolf, 1970; Vasyliunas, 1977; Yashura and Akasofu, 1977), and their shift in the dawn-dusk direction depends on the intensity of this gradient (de la Beaujardière et al., 1991).

Much interest has been devoted to the so-called Harang discontinuity, here defined as the velocity reversal, because the onset of substorms might occur on field lines connected in its vicinity, probably slightly equatorward of it (Robinson and Vondrak, 1990). Its location can be clearly identified in the premidnight sector of the auroral conductance belt, as a sharp boundary (see Figs. 6 and 7). For moderate magnetic activity $(K p=2-4)$, it remains confined at the polarmost latitudes of the field of view, decreasing by only $2^{\circ}$ in latitude from 19 to 22 MLT (Fig. 6). Then, between 22 and 23 MLT, it abruptly crosses equatorward the radar field of view, through a region of weak velocity amplitudes. Except that it appears earlier at the polarmost latitudes, it behaves similarly for higher $K p$, with a slow decrease in latitude from 17 to 21 MLT, and then a steep slope equatorward around 21 MLT (Fig. 7). Above $68^{\circ}-69^{\circ}$ invariant latitude, the orientation of the 
Harang discontinuity at small angle with respect to constant invariant latitudes departs from other statistical or steady-state convection models (for example, Heppner and Maynard, 1987). It reconciles the statistical approach with individual observations by ground-based radars, such the STARE radar in the same area (Nielsen and Greenwald, 1979; Koskinen and Pulkkinen, 1995). At lower latitudes, its orientation comes closer to the northsouth direction, which generally meets previous statistical or modelling views. These statistical velocity patterns also reveal another feature which might play a role in the understanding of the auroral electrodynamics: the plasma flow, intense in the regions adjacent to the Harang discontinuity, considerably reduces its amplitude across it, and even cancels. This result favors the description of the Harang discontinuity as a velocity shear without any substantial plasma flow across it, or at least an extremely reduced flow, rather than as a velocity rotation embedded in a continuous flow from one side of it to the other (Koskinen and Pulkkinen, 1995).

The third panels of Figs. 6 and 7 display the ionospheric current distribution. If the ionospheric conductances were uniform, the current distribution would obviously match the convection pattern. The presence of the enhanced auroral conductances thus appears to be responsible for an ionospheric current circulation precisely restricted within the auroral belt. In consequence, the largest current intensities are observed equatorward (poleward) of the corresponding region of large velocities for the westward (eastward) electrojet. In the radar field of view, the westward electrojet intrudes more deeply into the premidnight and evening sectors and at lower latitudes with increasing magnetic activity, as expected since earlier studies (Kamide et al., 1981). The current reversal between both electrojets, sometimes also called Harang discontinuity due to initial observations with ground-based magnetometers, will be referred here as "magnetic discontinuity" by way of contrast to the velocity shear already mentioned (see Koskinen and Pulkkinen, 1995, and references therein). Sim- ilarly to the velocity shear, it also takes the shape of a sharp boundary in the evening and premidnight sectors. In both statistical cases at moderate and higher magnetic activity, it is systematically located $1^{\circ}$ equatorward of the corresponding velocity shear (Kamide and Vickrey, 1983; Koskinen and Pulkkinen, 1995, and references therein). This difference, previously attributed to an effect of the measurement method from magnetometers integrating all currents over a large area, takes here a more physical meaning which is illustrated in Fig. 8 in the case $K p=4-6$ (other cases are similar). In a first approach, the Hall currents, parallel to the drift velocities, will match the velocity reversal and cannot be responsible for a shift. The Pedersen currents, perpendicular to the velocities, are predominantly flowing in the north-south direction. Over the whole evening and premidnight sectors, they also have an additional westward component, which, although small, tends to increase (decrease) the dominant westward (eastward) component of the Hall currents poleward (equatorward) of the velocity shear, and which contributes thus to shift the current reversal slightly equatorward of the velocity shear. Similar features, such as the presence of westward electric fields in a highly conductive evening ionosphere driving substantial westward Pedersen currents, are also observed in surges (Robinson and Vondrak, 1990 , and references therein).

Finally, the last panels of Figs. 6 and 7 display the distribution of field-aligned currents computed from the divergence of the horizontal currents, and already presented in the polar diagrams of Fig. 4. Obviously, the upward currents (dashed lines) map onto the auroral belt of the enhanced conductances, and they are expected to be at least partly carried by the corresponding precipitating electron fluxes. In contrast, the downward currents of regions 1 and 2 are flowing on the poleward morning and equatorward evening edges of the conductance region, respectively. The high-latitude part of the "electric" Harang discontinuity, weakly inclined with respect to the constant latitudes, coincides with the line of the
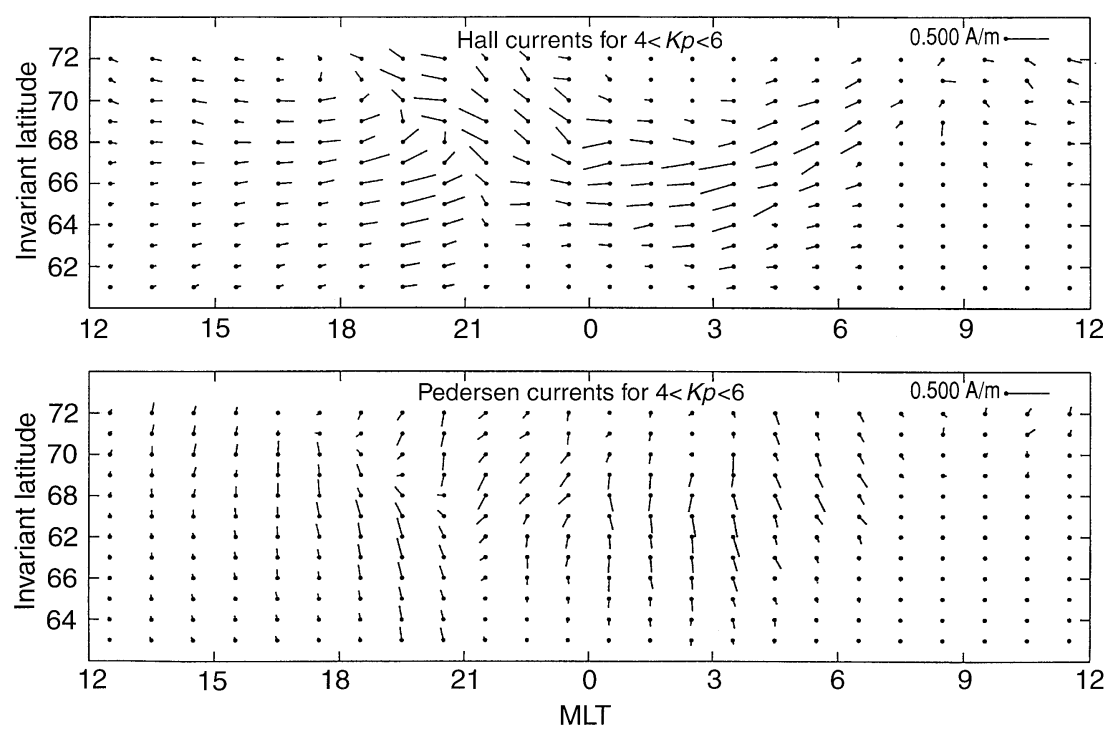

Fig. 8. Statistical distributions for $K p=4-6$ of Pedersen and Hall currents 
upward-current maxima in the evening region 1 , consistently with observations during active periods, while its equatorward steep part approximately separates upward and downward region-2 currents, as predicted by steady convection models.

\subsection{Current circuit}

The second topic that can be investigated from these statistical studies focuses on the structure of the threedimensional current system. The bottom panels of Figs. 6 and 7 illustrate the current circulation. In the evening sector, the field-aligned currents, flowing downward in region 2 , close through the conductive auroral ionosphere by the eastward electrojet (actually flowing rather in the northeast direction), which in turn connects to the region1 upward currents. Conversely, in the morning sector, the westward electrojet, approximately flowing in the southeast direction, connects the region-1 downward to the region-2 upward field-aligned currents. This is not the only connection undertaken by the westward electrojet: its westward part, which largely intrudes into the premidnight and evening sectors with a westward flow at the highest latitudes of the radar field of view, contributes to closing another current circuit at poleward latitudes between the region- 1 currents of both polarities. Conversely, we cannot evidence a similar connection by the auroral electrojets between the two sheets of opposite polarity in region 2 .

Finally, we examine the respective contribution to the total ionospheric current of the Hall currents, expected in presence of conductivity gradients, and of the Pedersen currents, mainly responsible for the closure of field-aligned currents. As an example, Fig. 8 displays their distributions in the case $K p=4-6$ (other cases are similar). Generally, the intensity of Hall currents somewhat exceeds the Pedersen current intensity, in the evening sector in particular, and might suggest a stronger control on ionospheric currents by the conductances rather than by the field-aligned currents. Although less intense, the Pedersen currents have non-negligible effects on the large-scale current circuit. Firstly, their global north-south orientation, combined with the mainly east-west Hall currents, contributes to the northeast (southwest) flow in the so-called eastward (westward) electrojets. Then, in the region of intrusion of the westward electrojet at the highest latitudes in the premidnight sector, the Pedersen currents, although weaker than the Hall currents, also play a specific role. Their southward component almost cancels out the northward component of the Hall currents, while their westward component adds to the dominant westward Hall component, resulting in a purely westward flow of the westward electrojet in this region, and closing the current circuit between the region-1 currents of both polarities.

\section{Conclusions}

From statistics for more than 3 years over the elevation scanning experiments with the EISCAT UHF radar,
Senior et al. (1990) and Senior (1991) derived empirical models, depending on the magnetic activity index $K p$, of the large-scale convection pattern and of the ionospheric conductances. Similarly, the same data base is used here to derive statistical models, over the same $K p$ ranges, of large-scale horizontal and field-aligned currents, which thus completes the description of the steady auroral electrodynamics previously initiated.

The results clearly show the intensification and the equatorward expansion of the whole current system, the deeper intrusion of the westward electrojet into the premidnight sector with the magnetic-activity level. Except for high-latitude dayside currents which remain poleward of the radar field of view, the intensity and the local-time variations are consistent with previously published models (Iijima and Potemra, 1976, 1978; Foster et al., 1989). Some minor differences exist with the results of Foster et al. (1989): the field-aligned current sheets forming regions 1 and 2 are statistically more narrow and the current intensity generally larger in region 1 than in region 2, consistent with Iijima and Potemra (1976, 1978). A morning-evening asymmetry can be clearly identified in the field-aligned current distribution: the evening sheets (especially region 2) are concentrated over a few hours around 18 MLT, while the morning sheets expand widely from premidnight to prenoon local times, similarly to the patterns inferred by Richmond et al. (1988).

We took advantage of the observation by EISCAT of a full set of ionospheric parameters to examine several aspects of the large-scale statistical auroral electrodynamics. The solar wind-magnetosphere interaction contributes to drive convection flows in the ionospheric plasma, which are particularly intense at the polar-cap boundary. On the nightside, these intense flows oriented from the polar cap equatorward are deflected by the conductivity gradients toward the morning and evening sectors. The Harang discontinuity is clearly identified in the evening and premidnight sectors. At the highest latitudes observed by the radar, it appears as a sharp velocity reversal, weakly inclined on the lines of constant latitudes, with intense flows directed toward it on both sides and extremely reduced velocities across it. This description, based on observations of one point of the Harang discontinuity per scan, better corresponds to a velocity shear rather than to a rotation at constant amplitude embedded in a continuous flow, as previously suggested by Koskinen and Pulkkinen (1995) from its actual two-dimensional orientation on convection maps. At these high latitudes, the Harang discontinuity coincides with the line of the maxima of the region-1 upward currents. At lower latitudes, its orientation rotates toward larger angles with respect to the constant latitudes: the Harang discontinuity crosses the radar field of view equatorward, typically between 22 and 23 MLT, through a region of weak velocities on both sides, as predicted by other statistical convection models, and it also marks the polarity reversal for region- 2 currents. The reversal between the eastward and westward electrojets, also interpreted as the "magnetic" signature of the Harang discontinuity, occurs systematically $1^{\circ}$ invariant latitude equatorward of the velocity reversal. This feature, also observed in the case of active 


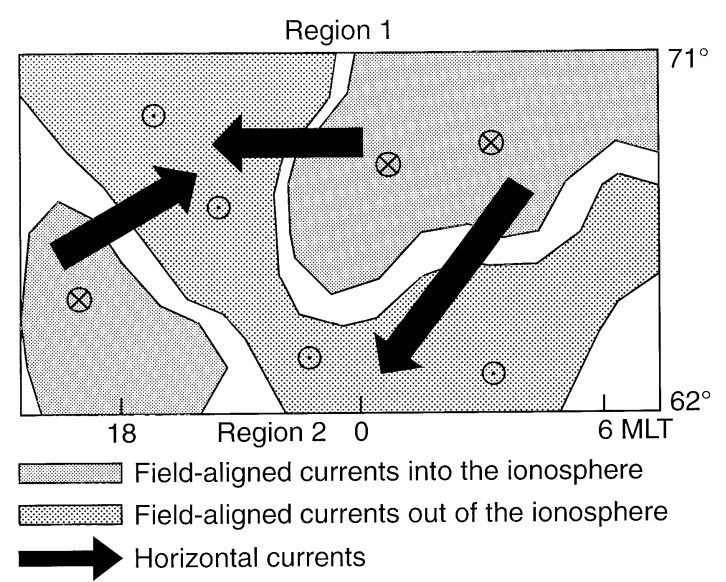

Fig. 9. Sketch of the current system on the nightside of the auroral ionosphere (note that there is no arrow pointing between the two current sheets of region 2)

surges, is attributed to the presence of a westward component of the Pedersen currents which adds to the dominant westward Hall currents to shift equatorward the current reversal with respect to the velocity reversal.

Figure 9 summarizes the main results on the global current circulation, as statistically observed by EISCAT in moderate and disturbed magnetic conditions. The case of weak activity is not discussed, because a large part of the current system remains poleward of EISCAT observations. Figure 9 is a sketch of the night part of the auroral ionosphere in the radar field of view. Upward field-aligned currents are connected to the enhanced conductance belt, which also contributes to drive the most intense ionospheric currents. Several current systems can be identified. The first, in the evening sector, describes a circulation from region-2 downward field-aligned currents, which close into the ionospheric conductive layer through the eastward electrojet, and are then diverted by region-1 upward field-aligned currents at higher latitudes. A second circulation can be similarly evidenced in the morning sector with an opposite polarity, from the region-1 downward currents, through the westward electrojet, to the region-2 upward currents at lower latitudes. Finally, poleward of the Harang discontinuity, the westward end of the westward electrojet widely intrudes into the premidnight and evening sectors. The Pedersen component of the currents adds to the dominant Hall component to contribute to the purely westward flow, observed in this region, and to the closure of a third current circuit connecting the region-1 field-aligned currents of both polarities. The adjacent current sheets of region-2 do not exhibit a similar connection. Outside this high-latitude premidnight sector, the combination of both Hall and Pedersen currents contributes to orientate the electrojet flows in an inclined direction (northeast-southwest). The larger intensity of the Hall component could indicate that the auroral conductances control more closely the auroral electrojets than the field-aligned currents.

The rich and complex electrodynamics related to particular events, such as the intense, narrow, and spiky structures observed during substorms by Fujii et al. (1994) for example, remain out of the scope of the present work. By smoothing out localized and short-lived phenomena, the present statistical models only exhibit the large-scale and steady trends of the auroral electrodynamics. However, it is remarkable that they resemble some features of individual active events. This is particularly obvious in the active premidnight sector where substorm onsets and surges are expected to occur. The auroral electrodynamics, statistically observed by EISCAT at the evening edge of the auroral enhanced conductivity belt, display intense flows of upward field-aligned currents, the intrusion of the westward electrojet into the evening sector with a mainly westward current flow, and a sharp velocity shear at the high-latitude Harang discontinuity colocated with the maxima of region-1 upward field-aligned currents (see Baumjohann et al., 1981). Except in the case of the lowest range of magnetic activity, which cannot be discussed because most features remain partly outside the radar field of view, these global trends become more pronounced with magnetic activity. We suggest that they may pre-exist in the auroral ionosphere before the subsequent development of surges or substorms, and that they locally intensify during active phases, in connection with magneto spheric processes, to exhibit particularly intense and variable signatures as observed.

Acknowledgements. The EISCAT facility is supported by the Research Councils of Finland (SA), France (CNRS), Germany (MPG), Norway (NAVF), Sweden (NFR), and the United Kingdom (SERC). The authors are grateful to C. Senior for the use of the data base of EISCAT Common Programs CP-3.

Topical Editor D. Alcaydé thanks H. E. J. Koskinen and another referee for their help in evaluating this paper.

\section{References}

Ahn, B.-H., H. W. Kroehl, Y. Kamide, and D. J. Gorney, Estimation of ionospheric electrodynamic parameters using ionospheric conductance deduced from bremsstrahlung X-ray image data, $J$. Geophys. Res., 94, 2565, 1989.

Alcaydé, D., G. Caudal, and J. Fontanari, Convection electric fields and electrostatic potential over $61^{\circ}<\Lambda<72^{\circ}$ invariant latitude observed with the European incoherent scatter facility, J. Geophys. Res., 91, 233, 1986

Baumjohann, W., R. J. Pellinen, H. J. Opgenoorth, and E. Nielsen, Joint two-dimensional observations of ground magnetic and ionospheric electric fields associated with auroral zone currents: Current system associated with local aurora breakups, Planet. Space Sci., 29, 431, 1981.

Brekke, A., and C. Hall, Auroral ionospheric quiet summer-time conductances, Ann. Geophysicae, 6, 361, 1988.

Caudal, G., Field-aligned currents deduced from EISCAT observations and implications concerning the mechanism that produces region-2 currents, J. Geophys. Res., 92, 6000, 1987.

Caudal, G., and M. Blanc, Using a constraint on the parallel velocity when determining electric fields with EISCAT, J. Atmos. Terr. Phys., 50, 383, 1988.

de la Beaujardière, O., D. Alcaydé, J. Fontanari, and C. Leger, Seasonal dependence of high-latitude electric fields, J. Geophys. Res., 96, 5723, 1991.

Folkestadt, K., T. Hagfors, and S. Westerlund, EISCAT: An update description of technical characteristics and operational capabilities, Radio Sci., 18, 867, 1983. 
Fontaine, D., S. Perraut, D. Alcaydé, G. Caudal, and B. Higel, Large-scale structures of the convection inferred from coordinated measurements by EISCAT and GEOS 2, J. Atmos. Terr. Phys., 48, 973, 1986.

Foster, J. C., J. M. Holt, R. G. Musgrove, and D. S. Evans, Solar wind dependencies of high-latitude convection and precipitation, in Solar Wind-Magnetosphere Coupling, Eds. Y. Kamide and J. A. Slavin, D. Reidel, Hingham, Mass., pp 477, 1986.

Foster, J. C., T. Fuller-Rowell, and D. S. Evans, Quantitative patterns of large-scale field-aligned currents in the auroral ionosphere, J. Geophys. Res., 94, 2555, 1989.

Friis-Christensen, E., Y. Kamide, A. D. Richmond, and S. Matsushita, Interplanetary magnetic field control of high-latitude electric fields and currents determined from Greenland magnetometer data, J. Geophys. Res., 90, 1325, 1985.

Fujii, R., R. A. Hoffman, P. C. Anderson, J. D. Craven, M. Sugiura, L. A. Frank, and N. C. Maynard, Electrodynamic parameters in the nighttime sector during substorms, J. Geophys. Res., 99, 6093, 1994.

Fuller-Rowell, T. J., and D. S. Evans, Height-integrated Pedersen and Hall conductivity patterns inferred from the TIROS-NOAA satellite data, J. Geophys. Res., 92, 7606, 1987.

Hardy, D. A., M. S. Gussenhoven, and E. Holeman, A statistical model of auroral electron precipitation, J. Geophys. Res., 90, 4229, 1985.

Hardy, D. A., M. S. Gussenhoven, R. Raistrick, and W. J. McNeil, Statistical and functional representations of the pattern of auroral energy flux, number flux, and conductivity, J. Geophys. Res., 92, 12275, 1987 .

Heppner, J. P., and N. C. Maynard, Empirical high-latitude electric fields models, J. Geophys. Res., 92, 4467, 1987.

Iijima, T., and T. A. Potemra, The amplitude distribution of fieldaligned currents at northern high latitudes observed by Triad, J. Geophys. Res., 81, 2165, 1976.

Iijima, T., and T. A. Potemra, Large-scale characteristics of fieldaligned currents associated with substorms, J. Geophys. Res., 83, 599, 1978.

Kamide, Y., and J. F. Vickrey, Variability of the Harang discontinuity as observed by the Chatanika radar and the IMS Alaska magnetometer chain, Geophys. Res. Lett., 10, 159, 1983.

Kamide, Y., A. D. Richmond, and S. Matsushita, Estimation of ionospheric electric fields, ionospheric currents and field-aligned currents from ground-based records, J. Geophys. Res., 86, 801, 1981.

Koskinen, H. E. J., and T. I. Pulkkinen, Midnight velocity shear and the concept of Harang discontinuity, J. Geophys. Res., 100, 9539, 1995.
Nielsen, E., and R. A. Greenwald, Electron flow and visual aurora at the Harang discontinuity, J. Geophys. Res., 84, 4189, 1979.

Reiff, P. H., Models of auroral conductance, in Magnetospheric Currents, Geophys. Monogr. Ser., vol. 28, Ed. T. A. Potemra, AGU, Washington, D. C., pp 180, 1984.

Richmond, A. D., and Y. Kamide, Mapping electrodynamics features of the high-latitude ionosphere from localized observations: Technique, J. Geophys. Res., 93, 5741, 1988.

Richmond, A. D., Y. Kamide, B. H. Ahn, S.-I. Akasofu, D. Alcaydé, M. Blanc, O. de la Beaujardière, D. S. Evans, J. C. Foster, E. Friis-Christensen, T. J. Fuller-Rowell, J. M. Holt, D. Knipp, H. W. Kroehl, R. P. Lepping, R. J. Pellinen, C. Senior, and A. N. Zaitsev, Mapping electrodynamic features of the high-latitude ionosphere from localized observations: Combined incoherentscatter radar and magnetometer measurements for January 18-19, 1984, J. Geophys. Res., 93, 5760, 1988.

Robinson, R. M., and R. R. Vondrak, Measurements of E-region ionization and conductivity produced by solar illumination at high latitudes, J. Geophys. Res., 89, 3951, 1984.

Robinson, R. M., and R. R. Vondrak, Electrodynamic properties of auroral surges, J. Geophys. Res., 95, 7819, 1990.

Schlegel, K., Auroral E-region conductivities during solar minimum derived from EISCAT data, Ann. Geophysicae, 6, 129, 1988.

Senior, C., Solar and particle contributions to auroral height-integrated conductivities from EISCAT data: a statistical study, Ann. Geophysicae, 9, 449, 1991.

Senior, C., D. Fontaine, G. Caudal, D. Alcaydé , and J. Fontanari, Convection electric fields and electrostatic potential over $61^{\circ}<\Lambda<72^{\circ}$ invariant latitude observed with the European incoherent scatter facility, 2. Statistical results, Ann. Geophysicae, 8, 257, 1990.

Vasyliunas, V. M., Mathematical models of the magnetospheric convection and its coupling to the ionosphere, in Particles and fields in the magnetosphere, Ed. B. M. McCormac, D. Reidel, Hingham, Mass., pp 60, 1977.

Vickrey, J. F., R. R. Vondrak, and S. J. Mathews, The diurnal and latitudinal variations of auroral-zone ionospheric conductivities, J. Geophys. Res., 86, 65, 1981.

Wallis, D. D., and E. E. Budzinski, Empirical models of heightintegrated conductivities, J. Geophys. Res., 86, 125, 1981.

Wolf, R. A., Effects of ionospheric conductivity on convective flow of plasma in the magnetosphere, J. Geophys. Res., 75, 4677, 1970.

Yashura, F., and S.-I. Akasofu, Field-aligned currents and ionospheric electric fields, J. Geophys. Res., 82, 1279, 1977.

Yashura, F., Y. Kamide, and J. M. Holt, Field-aligned currents in high latitudes estimated from Millstone Hill radar observations of ion drift, J. Geophys. Res., 87, 2553, 1982. 